
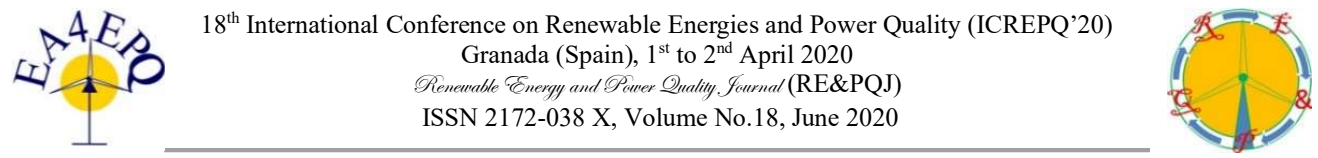

\title{
Combining photovoltaic modules and food crops: first agrovoltaic prototype in Belgium
}

\author{
Brecht Willockx ${ }^{1}$, Bert Herteleer ${ }^{1}$ and Jan Cappelle ${ }^{1}$ \\ ${ }^{1}$ Research Group Energy and Automation \\ Faculty of Engineering Technology, KU Leuven \\ Technologiecampus Ghent - Gebroeders Desmetstraat 1, 9000 Ghent (Belgium) \\ Phone/Fax number:+0032 472 321410, e-mail: brecht.willockx@kuleuven.be
}

\begin{abstract}
Agrovoltaic systems (combination of biomass production and electricity production by photovoltaics (PV)) are typically installed in locations with high insolation and/or arid climates in order to protect the crops against drought and sunburn. However, even in Belgium with a temperate maritime climate, summers are getting warmer and dryer, with reduced crop yields as result. This paper describes the first agrivoltaic prototype in Belgium. By use of a coupled simulation program developed in Python, a checkerboard panel arrangement was selected as an initial validation, in order to have a homogeneous ground radiation and crop growth. Potatoes were grown below the PV modules and the microclimate was measured. Results show lower temperatures below the PV modules and less transpiration and evaporation from crop and soil. The leaf area of the potatoes was larger below the PV modules which indicates an adapted light harvesting capability. Night-time temperatures were not seen to be improved under the agrivoltaic checkerboard structure, which indicates that this arrangement may not provide much protection against frost.
\end{abstract}

Key words. Agrivoltaic, agrovoltaic, proof-of-concept, dual land use, ground radiation simulation

\section{Introduction}

The European electricity system will have to be almost carbon-free by 2050 in order to achieve the European Union targets [1]; for this, increasing the share of renewable production is a requirement. Especially in Belgium, where there is a nuclear power phase-out planned in 2025 [2], the need to increase the share of renewable energy is high.

The share of solar photovoltaic energy in Belgium in 2017 was $3.7 \%$ of the total electricity production [3]. Currently, $44 \%$ of the arable area of Belgium is utilised for agriculture and horticulture, yet the most likely increasing population (and food demand) will make sure that food production always has priority over paving that agricultural area for solar parks [4]. Utility-scale solar farms require large amounts of land, which is scarce in Belgium, given its high population density. Moreover, on average, six hectares of open space disappears every day [5]. The combination of energy and crop production on the same land could offer a solution. Agrovoltaics is an innovative concept, implemented worldwide, with expertise in Asia and several pilot projects in Europe [6].

Most of these agrovoltaic installations are built in arid areas and places with a high amount of annual solar insolation $\left(>1300 \mathrm{kWh} / \mathrm{m}^{2}\right)$ [6]. The shade created by the PV array does not necessarily lead to loss of biomass yield. The expectation is that the shade from the PV structures may protect crops against drought stress and sunburn and thus be beneficial to the crop yield [6]. However, even in Belgium (annual mean insolation $1000 \mathrm{kWh} / \mathrm{m}^{2}$ ), summers are getting hotter and dryer [7] with reduced crop yields as a result [8], which explains the need to test agrivoltaic installations. This paper describes the first agrivoltaic prototype in Belgium and is structured as follows: section 2 describes the designing process, section 3 the building phase and section 4 the results. Finally in section 5, a general conclusion is made.

\section{Preliminary design}

According to Marrou et al. [9], the main changing parameter in agrovoltaic conditions is the ground solar radiation. This radiation has an influence on the photosynthetic process and transpiration of the crop, two elements with major influence on the crop yield [10]. The wavelengths important for crop growth are between $400 \mathrm{~nm}$ and $700 \mathrm{~nm}$ of the solar spectrum, and is called the photosynthetically active radiation (PAR).

In order to design an agrovoltaic system with a solid theoretical foundation, a simulation program to calculate solar radiation below PV modules was developed in Python [11]. This 3D simulation tool, based on an anisotropic view-factor model, is able to calculate the amount of direct and diffuse PAR-light on each point below the PV modules. Additionally, the PV energy yield is calculated by use of functions from pvlib [12]. The weather data for this simulation is obtained from the hourly TMY generator created by the Joint Research Centre of the European Commission [13]. 


\section{A. First design: straight-line arrangement}

A first simulation was made for a typical PV lay-out facing South, placed in Beernem, Belgium (Latitude: $51.127^{\circ} \mathrm{N}$; Longitude: $3.301^{\circ} \mathrm{E}, \mathrm{Cfb}$ Köppen-Geiger classification). The array consists of standard modules of $1 \mathrm{~m}$ wide and $1.66 \mathrm{~m}$ long, with a distance of $1.66 \mathrm{~m}$ between two rows, and tilted at $5^{\circ}$. Figure 1 shows the design of the first simulation.

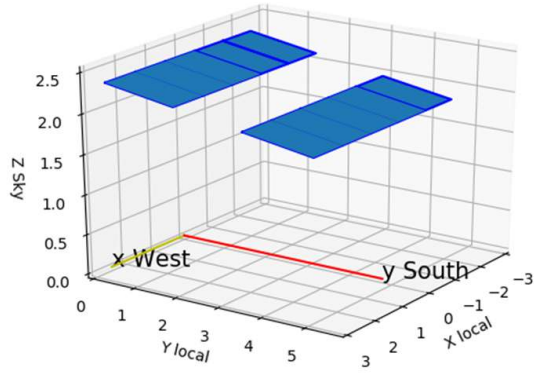

Figure 1: Straight line PV arrangement

The results from the simulation in Figure 2 shows a division of two areas: an area with a strong radiation reduction and an area of almost no radiation reduction. This has as result that the crops do not grow at the same rate, with a heterogeneous crop yield as result. This makes it difficult to harvest the field in one go [14]. To ensure homogeneous crop growth, homogeneous radiation exposure is preferable.

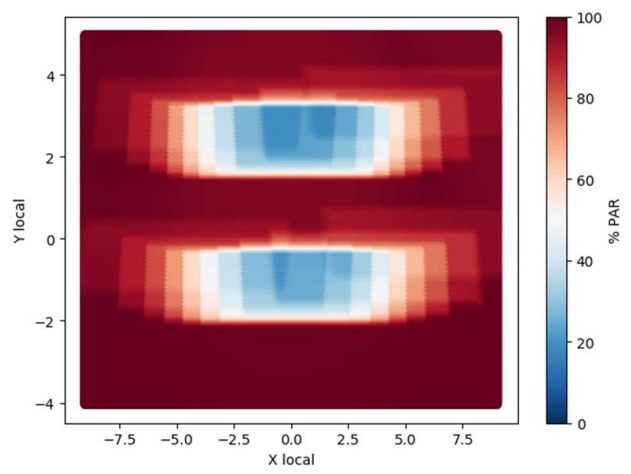

Figure 2: Annual percentage PAR at ground level in comparison with shade free environment, straight line

\section{B. Second design: checkerboard arrangement}

A possible solution for this heterogeneous ground radiation can be found by the design of photovoltaic greenhouses. Previous work [15-17] suggests that a checkerboard

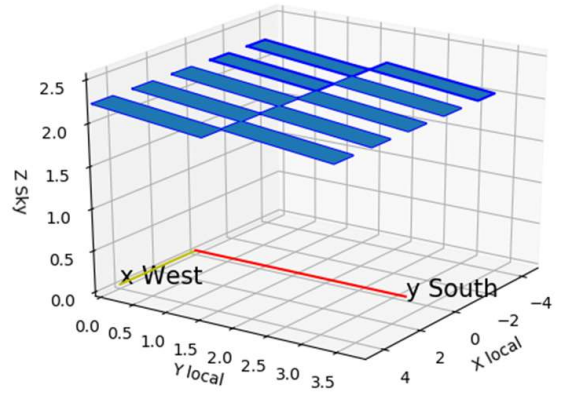

Figure 3: Checkerboard PV arrangement arrangement (as shown in Figure 3) will have a more uniform radiation distribution.

This homogeneous radiation distribution below PV modules is observed in Figure 4. Another observation is that the lowest PAR value in checkerboard arrangement is $15 \%$ higher than in the straight-line arrangement, which offers an advantage to limit crop yield losses, especially in Belgium where the absolute solar insolation is not that high.

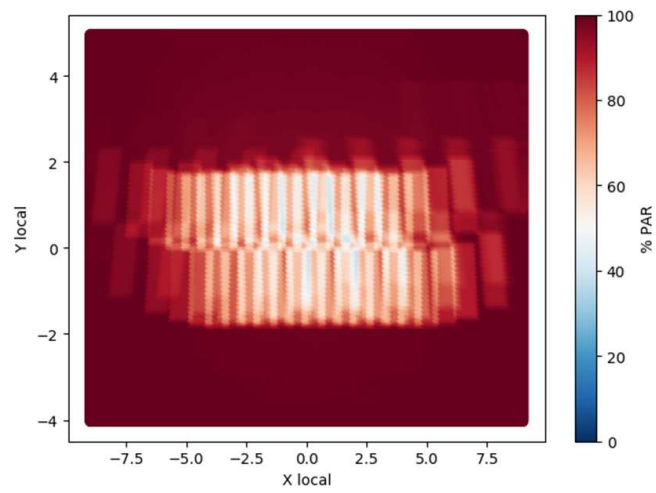

Figure 4: Checkerboard annual percentage PAR at ground level in comparison with shade free environment

\section{Energy production}

The generated PV power is simulated in Figure 5 for 10 PV modules of $280 \mathrm{Wp}$ with a constant module efficiency of $19 \%$ and system losses factor of $14 \%$ (i.e. temperature effects are neglected at this stage). The annual generated electricity is $2447 \mathrm{kWh}$ (specific yield $874 \mathrm{kWh} / \mathrm{kWp}$ ). The ground coverage ratio of the is equal for both arrangements (straight line versus checkerboard), what results in an equal annual energy production, expressed per hectare, while the crop production for both arrangements is expected to vary.

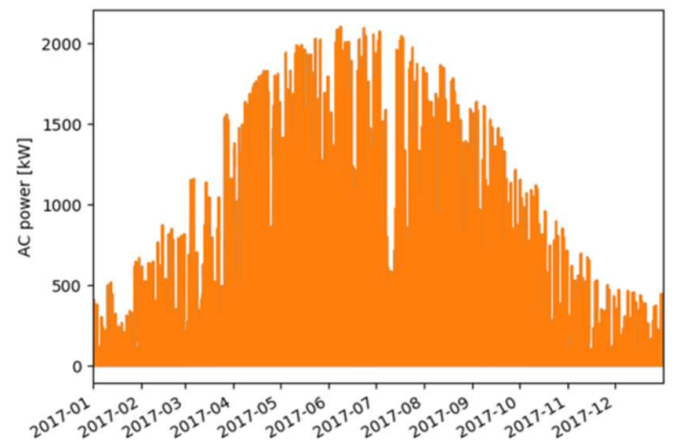

Figure 5: Modelled PV power production

\section{Building the proof of concept}

After the design optimization of the module layout in our simulation, a proof of concept has been built at the Beernem site used for simulation [18].

\section{A. PV structure}

Because this proof of concept is installed in an agricultural area there are some practical requirements: 
- No concrete anchoring, but temporary and reversible anchoring

- Enough space between pillars to allow (manual) farming practices

Therefore, the PV structure is $10 \mathrm{~m}$ wide and $2 \mathrm{~m}$ high to ensure that the land beneath it is cultivable and the posts are drilled $1.5 \mathrm{~m}$ deep without any concrete fixation, as shown in Figure 6.

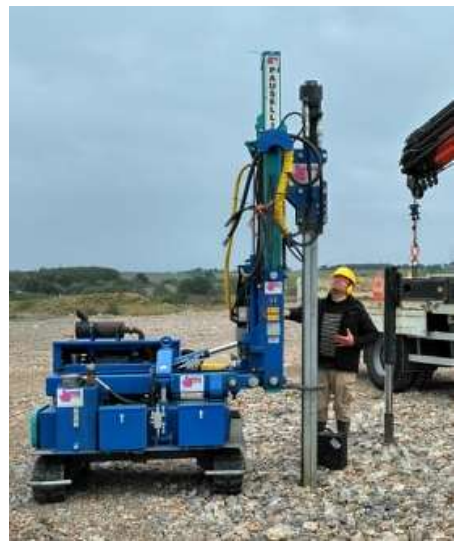

Figure 6: Drilling process

Figure 7 shows how two areas were defined: a reference area, without the influence of PV modules and an evaluation area below the PV modules in checkerboard arrangement.

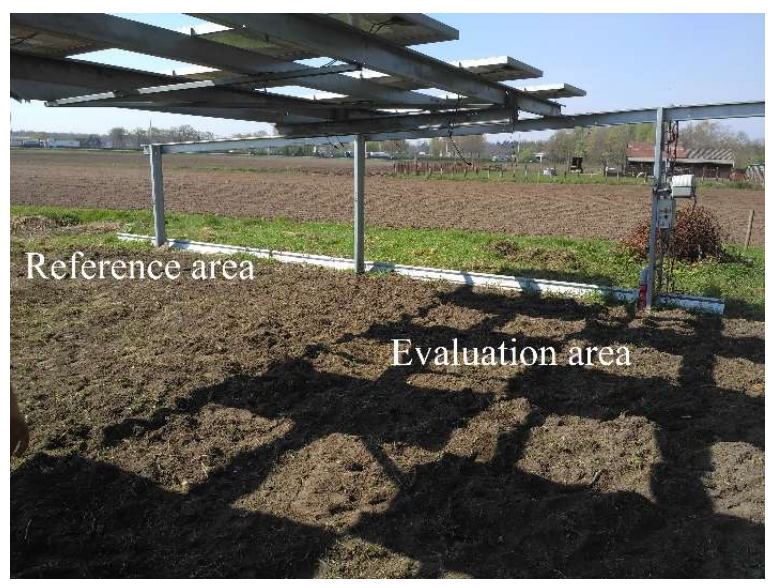

Figure 7: Division of reference and evaluation areas

\section{B. Sensors}

In order to measure the change in radiation between the reference and evaluation area, PAR sensors (Apogee SQ214 , accuracy $\pm 2 \%$ and $\pm 5 \%$ at solar zenith angles of $45^{\circ}$ and $75^{\circ}$ ) were installed in the reference and evaluation

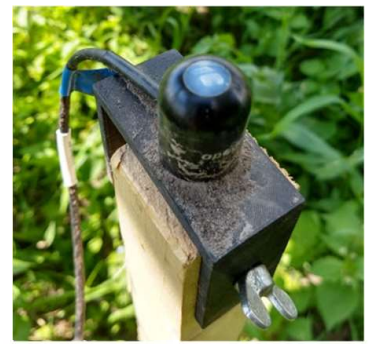

Figure 8: PAR sensors to measure the change in solar radiation below the $\mathrm{PV}$ modules areas. These measure the photon flux density, given in $\mu \mathrm{mol} / \mathrm{m}^{2} / \mathrm{s}$. An example of such a PAR sensor is shown in Figure 8. Temperature (accuracy $\pm 0.5^{\circ} \mathrm{C}$ ) and humidity sensors (accuracy $\pm 3 \%$ ) are added at height of $1.8 \mathrm{~m}$ to measure the micro-climatic conditions.

\section{Crop selection}

There is very little information about the shade tolerance of crops below PV modules (with exception of Marrou's study [19]). However, a first guess can be made by looking at the light response curve of the crop. The light response curve is expressing the photosynthesis rate in function of the received PAR light, as can be seen in Figure 9. At higher photon fluxes, the photosynthesis rate reaches saturation after which further increases in photon flux no longer affect photosynthetic rates. Crops can be divided in three groups according to the process of photosynthesis: C3, C4 and CAM [20]. The light saturation point is generally at a higher PAR levels for $\mathrm{C} 4$ crops (maize, sugarcane,...) than $\mathrm{C} 3$ crops (wheat, rice, potato,.. ), which makes $\mathrm{C} 3$ crops more suitable for agrovoltaic applications.

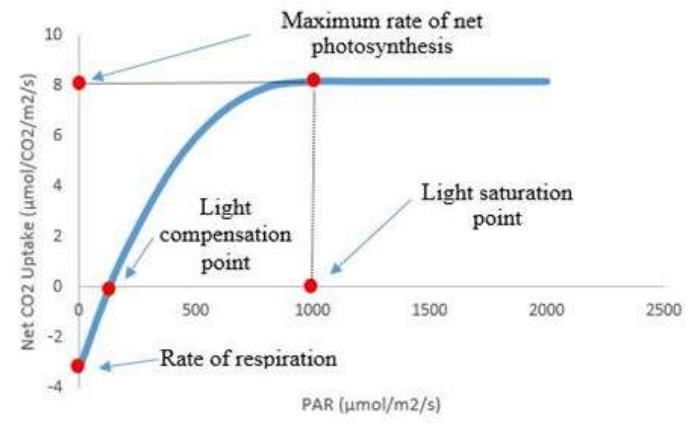

Figure 9: Light response curve [26]

Furthermore, it is interesting to look at the susceptibility of drought. The shade below the PV modules will probably result in less transpiration, which leads to a higher soil moisture, advantageous for the biomass yield of droughtsensitive crops [21].

An example of a typical (shade resistant) C3 crop that are sensitive to drought are potatoes [22]. For this proof-ofconcept, the Berber (Pedigree: Alcmaria x Ropta P 365) variety was used and planted on 15 April 2019. Figure 10 shows an example of the growing potatoes below the PV modules.

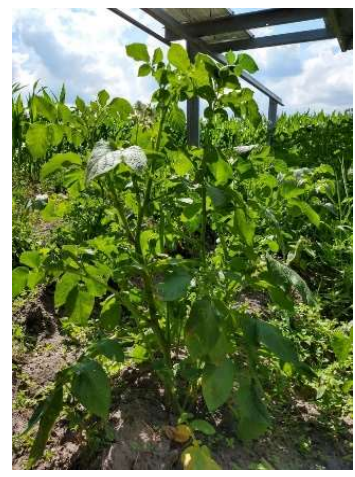

Figure 10: Potatoes growing below PV modules 


\section{Results}

The measured data was collected using a Siemens S7-1200 PLC system, equipped with a SQL database. The data was collected at a time resolution of 5 minutes. The measuring period ran between 24 April 2019 and 13 August 2019.

\section{A. Radiation below the PV modules}

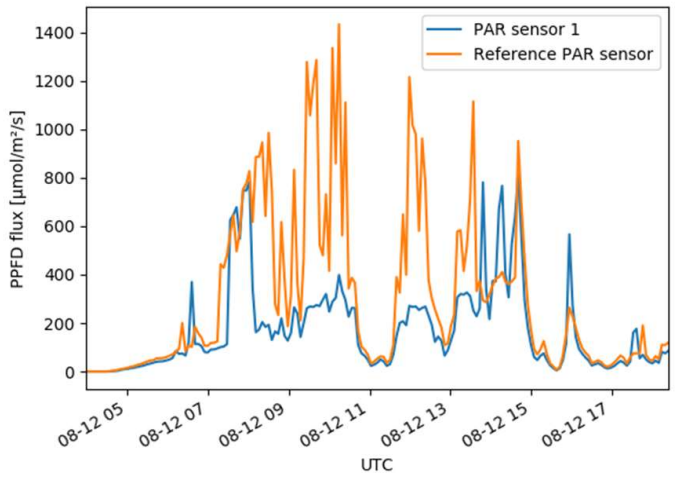

Figure 11: Measured PAR below PV modules and reference area on 12 August 2019

Figure 11 shows that the potato plants were shaded between 8 am and $2 \mathrm{pm}$. An erroneous measurement is observed between $2 \mathrm{pm}$ and $3 \mathrm{pm}$, where the value of the PAR sensor below the PV modules is higher than the value of the reference PAR sensor. This can probably be explained by the fact that the reference sensor has been shaded by the PV structure post.

The measured reference PAR data is used to validate the radiation model (from section 2). The Erbs model [23] is used to decompose the photon density flux into its direct and diffuse components. These direct and diffuse components are used in the radiation model and compared with real measured data from the PAR sensor below the PV modules.

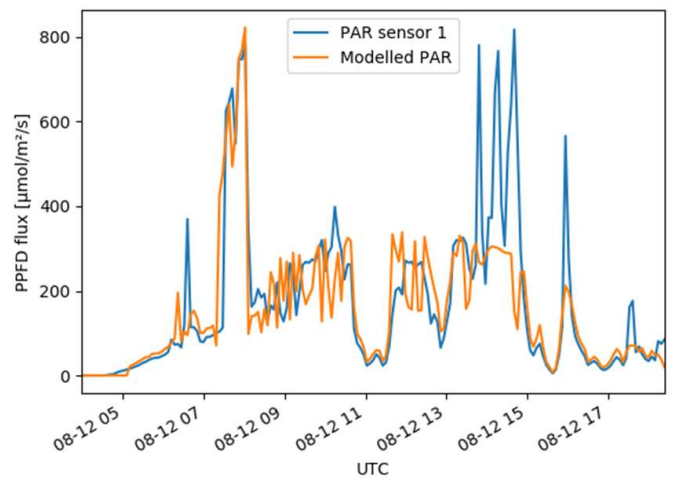

Figure 12: Comparison between measured and modelled PAR

It is clear in Figure 12 that the theoretical model follows general trend of the measured values from the sensor. Only when the measured reference sensor is shaded (which is used as input for the validation), the deviation error is large.

\section{B. Temperature and humidity}

When the temperature drops, the relative humidity increases, which is logical when the water vapour content stays the same. Colder air does not require as much moisture to become saturated as warmer air.

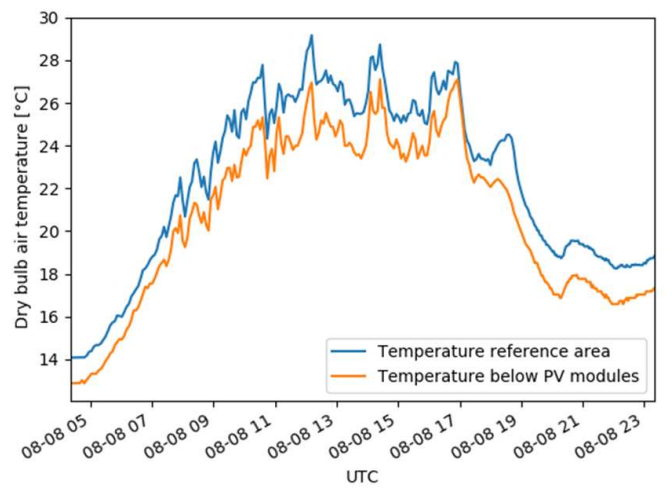

Figure 13: Measured dry bulb temperature in reference area and below PV modules on 8 August 2019

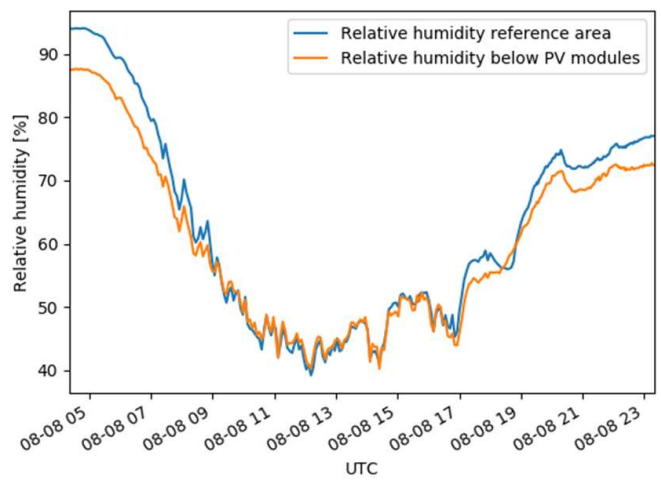

Figure 14 Measured relative humidity in reference area and below PV modules on 8 August 2019

With this information in mind, is it interesting to look at the difference between the reference area and evaluation area in Figure 13 and Figure 14. The reduction in the amount of radiation under the PV modules results in cooler daytime air temperatures, averaging a cooling effect of $1.65^{\circ} \mathrm{C}$ below the PV modules. Even during the night, the temperature below the modules remained lower than in the reference area, which is contradictory to results from other studies [9], [24], which claim that the temperature at night is higher due to the shelter effect of the PV modules. The difference can be explained by the fact that a checkerboard arrangement, with $50 \%$ gaps between the modules, has a less sheltered effect. This lower temperature could be beneficial to the crop yield, where global crop yields are expecting to be reduced due to the rising temperature as result of global warming [15], although this would not provide increased protection against frost.

At night, there is no transpiration of the crops in both areas and the water vapour content is equal in both areas. This has as result that the relative humidity is following the trend from the measured temperature, where the relative 
humidity is lower below the PV modules. During the day, even at a significant temperature difference, there is almost no difference in relative humidity noted between reference and evaluation area. This can be explained by the fact that there is less transpiration (due to less solar radiation) below the PV modules resulting in less water vapour content in the air. The reduced transpiration results in a reduced water demand, saving water for irrigation.

\section{Crop results}

After harvesting the potatoes, both the potatoes and the foliage were weighed and compared between the reference area and evaluation area. Remarkable was that the total leaf area for potatoes below the PV modules was larger than the reference area. It shows that potatoes have the ability to adapt to shaded conditions and can compensate the reduction of PAR radiation by a higher light harvesting capability, in this case with a higher leaf area. This has also been observed for lettuce [19].

\section{Conclusions}

A coupled simulation program that calculates the ground radiation influenced by PV modules and the produced electricity was developed in Python. By use of the simulation program, a checkerboard arrangement was modelled and subsequently tested with a prototype field.

The first agrovoltaic prototype was built, $2 \mathrm{~m}$ high and without concrete anchoring. This prototype was equipped with PAR sensors, to measure the change in solar radiation below the PV modules. Additionally, temperature and humidity sensors were added.

This checkerboard arrangement ensures a homogeneous irradiation distribution, resulting in homogeneous crop growth, which has been validated by the measured results. Remarkable is that potatoes are showing an improved light harvesting capability, with higher leaf areas.

Results of the measurements of the agrovoltaic prototype show that the temperature below the PV modules is consistently lower than in the reference area, which likely will be beneficial for biomass production in moderate and hot climates. The change in relative humidity indicates that there is less evaporation and transpiration below the PV modules, which protects crops against drought stress and saves water for irrigation.

In light of climate change with higher temperatures, agrovoltaic systems may protect the crops against drought and high temperatures. Different agrovoltaic designs would have to be modelled and considered to provide year-round protection in moderate climates, where frost is still an issue in winter.

\section{References}

[1] European Commission, "Energy roadmap 2050, page 5," European Union, Luxembourg: Publications Office of the European Union, 2012.

[2] FOD Economie, "Wettelijke grondslag van de kernuitstap in België," FOD economie, [Online]. Available:

https://economie.fgov.be/nl/themas/energie/energie bronnen/kernenergie/wettelijke-grondslag-van-de . [Accessed 25 October 2019].

[3] Statbel (Directorate-general Statistics - Statistics Belgium), "Gross electricity production 2017," 2017. [Online]. Available:

https://bestat.statbel.fgov.be/bestat/api/views/3a02 2b3b-b0fa-4d1e-bc91-62a0f632238c/result/HTML. [Accessed 28 October 2019].

[4] Vlaams infocentrum land-en tuinbouw, "Kleine kans op grote zonneparken in agrarisch gebied," VILT, 04 January 2019. [Online]. Available: https://www.vilt.be/kleine-kans-op-grotezonneparken-in-agrarisch-gebied. [Accessed 10 October 2019].

[5] Flemish Government, Department of Agriculture and Fisheries, "CHALLENGES FOR FLEMISH AGRICULTURE AND HORTICULTURE," Flemish Government, 2018.

[6] A. Weselek, A. Ehmann, S. Zikeli, I. Lewandowski, S. Schindele and P. Högy, "Agrophotovoltaic systems: applications, challenges, and opportunities. A review," Agronomy for Sustainable Development, Vols. https://doi.org/10.1007/s13593-019-0581-3, p. 20, 2019.

[7] R. Vautard, O. Boucher, G. J. van Oldenborgh, F. Otto, K. Haustein, M. M. Vogel and S. I.

Seneviratne, "Human contribution to the recordbreaking July 2019 heat wave in Western Europe," World Weather Attribution, 2019.

[8] De Standaard, "Droogte decimeert aardappel- en maïsoogst," De Standaard , 13 April 2019. [Online]. Available: https://www.standaard.be/cnt/dmf20190413_04320 855. [Accessed 27 October 2019].

[9] H. Marrou, L. Guilioni, L. Dufour, C. Dupraz and J. Wery, "Microclimate under agrivoltaic systems: Is crop growth rate affected," Agricultural and Forest Meteorology, vol. 177, no. http://dx.doi.org/10.1016/j.agrformet.2013.04.012, p. 18, 2013.

[10] C. Campillo Mario, R. Fortes and H. P. Maria, "Solar Radiation Effect on Crop Production," in Solar Radiation, InTechOpen, 2012, p. 29.

[11] B. Willockx, S. Bram and J. Cappelle, "Masterthesis: Agrivoltaics," BRUFACE Brussels, Brussels, 2018-2019.

[12] W. F. Holmgren, C. W. Hansen and M. A. Mikofski, "pvlib python: a python package for modeling solar energy systems," Journal of Open 
Source Software, no.

https://doi.org/10.21105/joss.00884, p. 3, 2018.

[13] European Commission Joint Research Centre, , “ PHOTOVOLTAIC GEOGRAPHICAL INFORMATION SYSTEM : TMY Generator," European Commission Joint Research Centre, 21 September 2017. [Online]. Available: https://re.jrc.ec.europa.eu/pvg tools/en/tools.html\# TMY. [Accessed 18 October 2019].

[14] M. Beck, G. Bopp, A. Goetzberger, T. Obergfell, C. Reise and S. Schindele, "Combining PV and food crops to agrophotovoltaic - optimazation of orientation and harvest," in 27th European Photovoltaic Solar Energy Conference and Exhibition, Frankfurt, Germany, 2013.

[15] Z. Chuang, L. Bing, P. Shilong, W. Xuhui, L. David, H. Yao, H. Mengtian, Y. Yitong, S. Bassu, P. Ciais, J.-L. Durand, J. Elliott, F. Ewert, I. Janssens, L. Tao, E. Lint, Q. Liua, P. Martreu and C. Mül, "Temperature increase reduces global yields of major crops in four independent estimates," Proceedings of the National Academy of Sciences, vol. 14, no. 10.1073/pnas.1701762114, p. 9326-9331, 2017.

[16] M. Cossu, A. Cossu, P. Deligios, L. Ledda, Z. Li, H. Fatnassi, C. Poncet and A. Yano, "Assessment and comparison of the solar radiation distribution inside the main commercial photovoltaic greenhouse types in Europe," Renewable and Sustainable Energy Reviews, vol. 94, no. 10.1016/j.rser.2018.06.001, 2018.

[17] A. Yano, M. Kadowaki, A. Furue, N. Tamaki, T. Tanaka, E. Hiraki, Y. Kato, F. Ishizu and S. Noda, "Shading and electrical features of a photovoltaic array mounted inside the roof of an east-west oriented greenhouse," Biosystems Engineering, vol. 106 , no.

https://doi.org/10.1016/j.biosystemseng.2010.04.00 7, pp. 367-377, 2010.

[18] T. Van Schuylenbergh, B. Willockx and J. Cappelle, "Het potentieel van Agrivoltaics in Vlaanderen," KU Leuven, Technologiecampus Gent, 2018-2019.
[19] H. Marrou, J. Wery, L. Dufour and C. Dupraz, "Productivity and radiation use efficiency of lettuces grown in the partial shade of photovoltaic panels," European Journal of Agronomy, vol. 44, no. 10.1016/j.eja.2012.08.003, pp. 54-66, 2012.

[20] D. Rintoul, R. Bear, B. Snyder, M. Smith-Caldas, C. Herren and E. Home, Principles of Biology, pages $535-540$, https://legacy.cnx.org/content/col11569/1.27: CNX, 2018

[21] H. Marrou, L. Dufour and J. Wery, "How does a shelter of solar panels influence water flows in a soil-crop system?," European Journal of Agronomy, vol. 50, no. 10.1016/j.eja.2013.05.004, pp. 38-51, 2013.

[22] P. Monneveux, D. Ramírez, A. Khan, R. Raymundo, H. Loayza and R. Quiro, "Drought and heat tolerance evaluation in potato," in Triennial Conference EAPR2014, Brussels, 2014.

[23] D. G. Erbs, S. Klein and J. A. Duffie, "Estimation of the diffuse radiation fraction for hourly, daily and monthly-average global radiation," Solar Energy, vol. 28, pp. 293-302, 1982.

[24] G. A. Barron-Gafford, M. A. Pavao-Zuckerman, R. L. Minor, L. Sutter, I. Barnett-Moreno, B. Daniel T, M. Thompson, K. Dimond, A. K. Gerlak, G. P. Nabhan and J. E. Macknick, "Agrivoltaics provide mutual benefits across the food-energy-water nexus in drylands," Nature sustainability, vol. 2, no. https://doi.org/10.1038/s41893-019-0364-5, p. 848-855, 2019.

[25] H. Fatnassi, C. Poncet, M.-M. Bazzano, R. Brun and N. Bertin, "A numerical simulation of the photovoltaic greenhouse microclimate," Solar Energy, no. 10.1016/j.solener.2015.07.019, 2016.

[26] J. C. Lopez, "Influence of Light on Crop Growth," pthorticulture, 5 October 2018. [Online]. Available: https://www.pthorticulture.com/en/trainingcenter/influence-of-light-on-crop-growth/. [Accessed 10 October 2019]. 